\title{
Analysis of the Dependence on Economic Growth in China to Energy Consumption
}

\author{
Yongming Pan ${ }^{a}$, Jing Wang ${ }^{b}$ \\ School of Management, Tianjin University of Technology, Tianjin, China \\ apym-tj@sina.com, b1311801661@qq.com
}

Keywords: economic growth, energy consumption, optimize the industrial structure, improve energy efficiency.

\begin{abstract}
In recent years, China's economic development has attracted worldwide attention, but economic growth has been at the expense of the excessive consumption of energy. Per unit of GDP's energy consumption in China is not only much higher than the United States, Japan and other developed countries that are far higher than the world average. On basis of simple analysis on the cause of excessive energy consumption in our country, this paper uses the econometrics method to study the various factors in the economic growth and how they affect the level of the energy consumption. Finally, this paper puts forward the proposal of optimize the industrial structure in our country, as well as development of new energy and so on. Only in this way can we at the same time in the guarantee of our country's economic growth and reduce energy consumption, which improve the effect of energy efficiency achieved particularly remarkable.
\end{abstract}

\section{The present situation and reason of economic growth and energy consumption in our country}

The speed of economic growth in China has attracted worldwide attention, at the same time, our country's energy consumption is worrying for a time. While promoting the development of economy, per unit of GDP 's energy consumption in our country is much higher than the world average. It can be say,our country's economic growth always adopts a development way which is extensive. This way could promote the economic growth in the short term, however, as the drying up of the non-renewable energy in our country, the disadvantages of this kind of development is increasingly significant.

Although the added value of the second industry and the third industry in China has been in ascension. But it is undeniable that the result of rapid development of economy is the growing demand for energy. Since 2000, our country's energy production and consumption rate continued to rise, growing faster than any period since the reform and opening up. 《Chinese Development Report (2013) 》 pointed out that, according to our country,per unit GDP's energy consumption is 0.49 , while the United States is 0.15 , Japan is 0.08 , and the average level of developing countries is 0.36 . The astonishing development speed in our country is largely backed up by high energy consumption. Energy, as well as pollution of the environment, promoted our country's economic growth for a long time.

As for the present situation of energy consumption in our country, energy and economy is the important subject of the national economic development. The investment in the energy industry has been increasing, it has to do with China's growing energy consumption status. It can be seen from table 1, from 2000 to 2013, China's total energy consumption rose from 1.455 billion tons of standard coal to 4.169 billion tons of standard coal, Consumption has increased by 2.86 times.

Meanwhile, one-time energy production and consumption has accounted for the proportion of over $90 \%$ of the total energy consumption in our country, mainly coal consumption, followed by oil and gas consumption. With the development of science and technology in recent years, the proportion of water and electricity, nuclear power and wind power consumption increased. This is the main trend of energy consumption of our country at present. At the same time, our country's energy loss has not 
been more effectively control, energy loss and energy consumption almost synchronous growth in our country. Excessive energy demand, with the limited production capacity and energy efficiency, causes our country's energy imports increased by 4.3 times in recent ten years.

Table 1 the situation of energy consumption in our country from 2000 to 2013

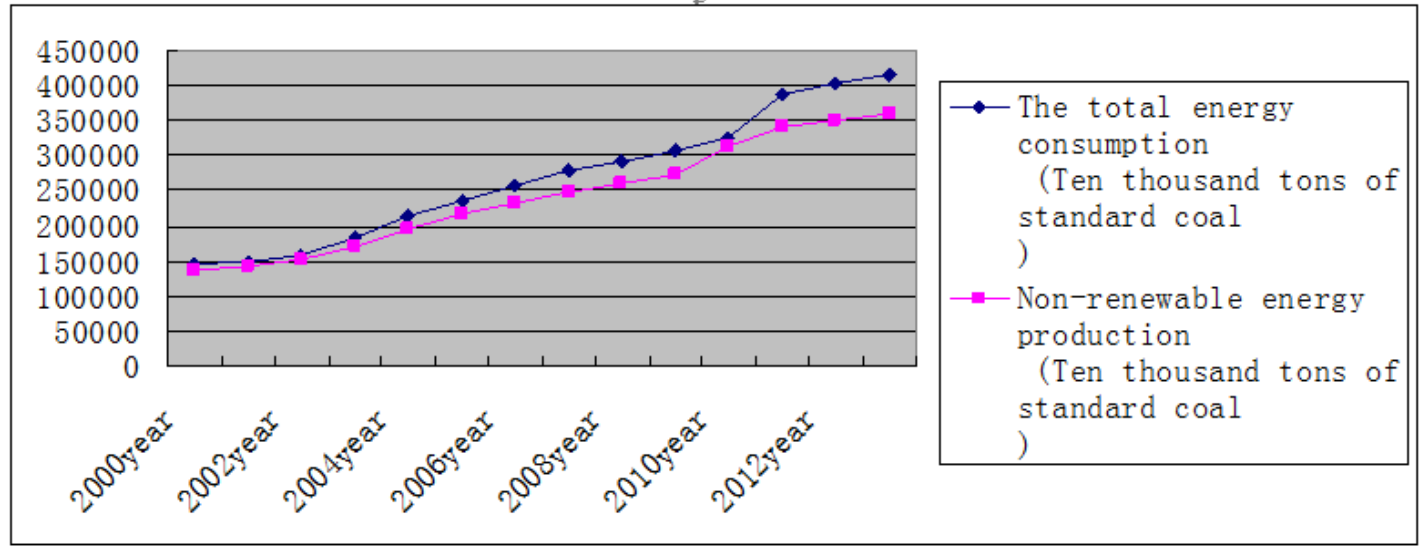

Source: national bureau of statistics 《China statistical yearbook $(2000 \sim 2013) 》$

The rapid growth of the demand for energy consumption related to the development situation of our country's economy at the present stage. First of all, with the growth of the national economy, the pace of the industrialization, the urbanization and informatization is accelerating, and residents' consumption level is rising,too. With more and more urban population, energy consumption intensity in the city is much higher than in rural areas. Among them, the housing area continues to expand, maintaining daily life consumption, etc., are all caused urban energy products to increase.The supply of water, heat, as well as gas, was significantly boost the energy consumption demand in urban. On the other hand, urban population increase and the consumption structure upgrade makes urban infrastructure investment increasing. The size of the transportation in the city's expansion and the growth of private car ownership are all make oil, electricity and other energy consumption greatly ascend.

Second, it related to the unreasonable industry structure at the present stage in China. In the industrialization stage, some traditional energy-intensive industries is still occupy large proportion in the economic structure in our country, while the development of the high and new technology industry is limited. Generally, the production level of the energy-intensive industries is lag behind others. Besides, these equipment is aging and overcapacity. This further increased the energy consumption in our country.

\section{Establishing and testing the econometric model}

In order to verify the influence of different factors on the energy consumption in our country, this article selects the data from 2000 to 2013 , among them ,this article uses the total energy consumption in our country as the explained variable, explanatory variables including China's gross domestic product (GDP) in each year and part of high energy consumption factors in our country mentioned above.

This paper intends to establish multiple linear regression model as follows:

$\mathrm{Y}=\beta_{0}+\beta_{1} \mathrm{X}_{1}+\beta_{2} \mathrm{X}_{2}+\beta_{3} X_{3}+\beta_{4} X_{4}+u$

With $Y$ represents the the total energy consumption in our country, the unit is ten thousand tons of standard coal; $\mathrm{X}_{1}$ represents the gross domestic product (GDP); $\mathrm{X}_{2}$ represents the private car ownership in the whole society; $\mathrm{X}_{3}$ represents the employment of the second industry in China; $\mathrm{X}_{4}$ represents the total energy use efficiency.

Using Eviews5.0 software, this paper analyzes the data in table 1, the results are shown in the below table: 


\begin{tabular}{|c|c|c|c|c|}
\hline Variable & Coefficient & Std. Error & t-Statistic & Prob. \\
\hline X1 & 0.668952 & 0.339419 & 1.970877 & 0.0842 \\
\hline X2 & -19.78859 & 11.41103 & -1.734163 & 0.0211 \\
\hline X3 & 4.092551 & 8.011086 & 0.510861 & 0.6232 \\
\hline X4 & 16199.96 & 5364.926 & 3.019605 & 0.0166 \\
\hline C & -1083163. & 363948.5 & -2.976144 & 0.0177 \\
\hline R-squared & 0.986004 & Mean dependent var & 250812.7 \\
\hline Adjusted R-squared & 0.979006 & S.D. dependent var & 75597.16 \\
\hline S.E. of regression & 10953.45 & \multicolumn{2}{|c|}{ Akaike info criterion } & 21.72442 \\
\hline Sum squared resid & $9.60 \mathrm{E}+08$ & \multicolumn{2}{|c|}{ Schwarz criterion } & 21.94171 \\
\hline Log likelihood & -136.2087 & \multicolumn{2}{|c|}{ F-statistic } & 140.8995 \\
\hline Durbin-Watson stat & 1.567684 & \multicolumn{2}{|c|}{ Prob(F-statistic) } & 0.000000 \\
\hline
\end{tabular}

According to the results of figure 1, we can establish the regression analysis model as follows:

$\mathrm{Y}=0.669 \mathrm{X}_{1}-0.19 .789 X_{2}+4.093 X_{3}+16199.96 \mathrm{X}_{4}-1083163$

Then test the goodness of fit of the model. It can be seen from the results of regression estimate, the model fitting is good.The affirmative coefficient $\mathrm{R}^{2}$ is 0.986004 , indicates that the joint of the variables in the economic growth can explain energy consumption in China perfectly.

When testing the Equation of significance, it can be seen from the table that the $F$ value is 175.0124, so the equation is significantly.

Then in this paper, the model is further optimized.The method is to make stepwise regression for this equation. The final result is shown in the following table:

\begin{tabular}{|c|c|c|c|c|}
\hline Variable & Coefficient & Std. Error & t-Statistic & Prob. \\
\hline X2 & 3.717655 & 4.599535 & 2.808268 & 0.0057 \\
\hline X3 & 17.88179 & 8.512325 & 4.100694 & 0.0097 \\
\hline X4 & 1198.002 & 3194.899 & 2.374973 & 0.0031 \\
\hline C & -174167.0 & 320133.4 & -6.544045 & 0.0098 \\
\hline AR(1) & 0.860916 & 0.363324 & 2.369556 & 0.0040 \\
\hline AR(2) & -0.244584 & 0.228337 & -3.071154 & 0.0031 \\
\hline R-squared & 0.998073 & Mean dependent var & 269511.6 \\
\hline Adjusted R-squared & 0.996146 & \multicolumn{2}{|c|}{ S.D. dependent var } & 66005.45 \\
\hline S.E. of regression & 4097.573 & \multicolumn{2}{|c|}{ Akaike info criterion } & 19.77663 \\
\hline Sum squared resid & 83950503 & \multicolumn{2}{|c|}{ Schwarz criterion } & 19.99366 \\
\hline Log likelihood & -102.7715 & \multicolumn{2}{|c|}{ F-statistic } & 517.9629 \\
\hline Durbin-Watson stat & 2.836266 & \multicolumn{2}{|c|}{ Prob(F-statistic) } \\
\hline Fin
\end{tabular}

Finally this article establishes the regression model:

$\mathrm{Y}=3.72 X_{2}+17.89 X_{3}+1198.00 X_{4}-174167.0+(\mathrm{AR}(1)=0.861)+(\mathrm{AR}(2)=-0.245)$

\section{Conclusion analysis and relevant policy recommendations}

The above analysis process optimizes and measures the model well. Through the model, we can draw the following conclusions.

\subsection{The relevant conclusion}

Among the factors that promoting the economic growth in China, the accelerating pace of urbanization, and the escalating of people's consumption structure has a huge influence in promoting energy consumption. The negative effect of this pattern of economic development is obvious. Keeping up, the sustainable development of our country's economy will be restricted, and this will bring a series of problems such as environmental pollution, the greenhouse effect, and so on. 


\section{2 the policy recommendations}

Economic growth will inevitably causes varying degrees of energy consumption, and,energy consumption, in turn, will stimulate the economic growth of China. But in the long run, China's energy consumption intensity must be properly controlled. Excessive energy consumption is not only negative to the sustainable development of economy in our country, when the economic development to a certain extent, it will restrict the economic growth. Therefore measures must be taken to improve our own situation, under the premise of economic growth. In this paper, the author suggests from the following several aspects to consider.

First, to optimize the industrial structure in our country. We should vigorously promote the development of the third industry, improve the proportion of the third industry in the national economy, at the same time, gradually reduce the proportion of the secondary industry, especially energy-intensive heavy industry. Only in this way, the industrial structure in our country can be rationalized.

Second, we can start from the introduction of high-tech and energy-saving technology, to improve the efficiency of energy use. This requires us to reduce the energy loss rate, improve the energy recovery technology, and reduce the waste of energy.

Third, to optimize our energy structure, and increase the investment in the field of new energy industry. In addition, the government can through the way of carbon tax levy, to inhibit the development of energy-intensive industries step by step. And by using of new energy, the government can indirectly support for the new energy industry.

\section{References}

[1]XiaoTao,Zhang zongyi . Based on co-integration and VECM study on the relationship between the energy consumption and economic growth, from China's experience:1990-2008 [J]. Soft science,2011(2).

[2]GuoShouqian,MaZhenzhen. China's economic growth and energy consumption decoupling relationship research $[\mathrm{J}]$. Statistics and decision 2012(13)

[3] 《China statistical yearbook(2000 2013)》.

[4]Kraft J,Kraft A.On the relationship between energy and GNP [J],Energy Development, 1978, 3 : $401-403$.

[5]Chien-Chiang L,Chang chunping.Energy consumption and economic growth in Asian economies:a more comprehensive analysis using panel data[J].Resouce and Energy Ecomomics 2008,30:50-65.

[6]Ping-huang Hsieh,Chand ra Smishra.The Return on R\&D Versus Capital Expenditures in Phamaceutical and Cheampal Industries[J],Transactions on Engineering Management, 2003, (5): $141-150$.

[7]Bosworth Hwang,David Gum. The Relationship between Energy and Economic Growth Time Series Evidence from Asian Developing countries[J],Energy Economics,2000,22:309_317. 